\title{
Sin comunidad ¿Hacia experiencias diluidas en un patrimonio desarraigado?
}

Juan Sevilla Álvarez | Dpto. de Geografía, Universidad de Oviedo

URL de la contribución <www.iaph.es/revistaph/index.php/revistaph/article/view/4498>

\begin{abstract}
¿En qué reside la esencia de lo patrimonial?
Los elementos patrimoniales se conciben, por parte de agentes intelectuales, institucionales y sociales -incluidas las iniciativas ciudadanas, organizadas o espontáneas-, como bienes a apreciar, divulgar, conservar y compartir dado que en ellos reside la perduración y la reafirmación de valores que tienen trascendencia social por constituir una expresión rica del espacio de vida, de la memoria y de las prácticas de una colectividad (GUILLAUME, 1990; BERDOULAY, 1992; BÉGHAIN, 1998; BOUISSET; DEGRÉMONT; SEVILLA, 2010; FERNÁNDEZ SALINAS; SILVA PÉREZ, 2015).
\end{abstract}

\section{Un factor creciente para el desarrollo territorial}

Los elementos del patrimonio cultural, entendidos como se ha expuesto, tienden a aprovecharse como recurso en estrategias de desarrollo territorial. En un contexto de expansión del hecho turístico en muy variadas modalidades, así como de la actividad académica y científica, la visita y el estudio de bienes patrimoniales tienen una repercusión que muchos organismos y agentes económicos desean aprovechar: estimulan la investigación y la formación avanzada de la población; dinamizan, diferencian y posicionan la imagen turística de un lugar, la oferta derivada y su mercado laboral, tendiendo un puente entre una cultura con vocación pedagógica y el ocio; al tiempo, favorecen el desarrollo de otros sectores de actividad, como el comercio, la hostelería, etc. (LOIS GONZÁLEZ; PIÑEIRA MANTIÑÁN; SANTOMIL MOSQUERA, 2010; FERNÁNDEZ SALINAS; SILVA PÉREZ, 2017).

\section{La puesta en valor de atributos reconocidos}

El vínculo entre la valoración patrimonial y el desarrollo turístico tiene que ver, en buena medida, con el disfrute de aquello que se considera inhabitual, de lo que resulta inesperado o de lo que no se ha conocido previamente. Se relaciona con la satisfacción de expectativas en lugares reconocidos por favorecer determinados tipos de aprovechamiento muy apetecidos: el gozo sensorial, el aprendizaje sociocultural, el bienestar físico, el descanso, etc. La atracción se explica por una identificación de cualidades en el elemento patrimonial que deriva de criterios compartidos colectivamente, en ocasiones difundidos por agentes externos pero muchas veces inducidos, consciente o inconscientemente, por la comunidad local en su vivencia del lugar (ZUBE; SELL; TAYLOR, 1982; ORMAETXEA ARENAZA; LUCIO FERNÁNDEZ, 1992; SEVILLA ÁLVAREZ; RODRÍGUEZ PÉREZ, 2019).

\section{La comunidad como partícipe}

La evolución de los estudios sobre el patrimonio cultural ha venido a subrayar el papel de las comunidades locales como actores protagonistas en la construcción del sentido que porta el bien patrimonial (BÉGHAIN, 1998). Ese protagonismo adquiere interés, además, en la elaboración de estrategias para el desarrollo, al ser la población más estrechamente vinculada la que mejor puede articular la puesta en valor del patrimonio, apoyándose en un trabajo científico, técnico e institucional tanto más valioso si en él participa la propia comunidad; lo que enlaza con los principios del desarrollo endógeno, en el que, a través de la coparticipación, se favorece la cohesión social (RODRÍGUEZ GUTIÉRREZ, 2012).

\section{La dinámica demográfica como condicionante}

Tenidos en cuenta la extensión contemporánea de la noción de patrimonio y el papel que puede acumular la comunidad, compartiendo saberes y prácticas en una red de relaciones densa (JOVER BÁEZ, 2019), es dif́cil pensar en un elemento patrimonial plenamente inter- 


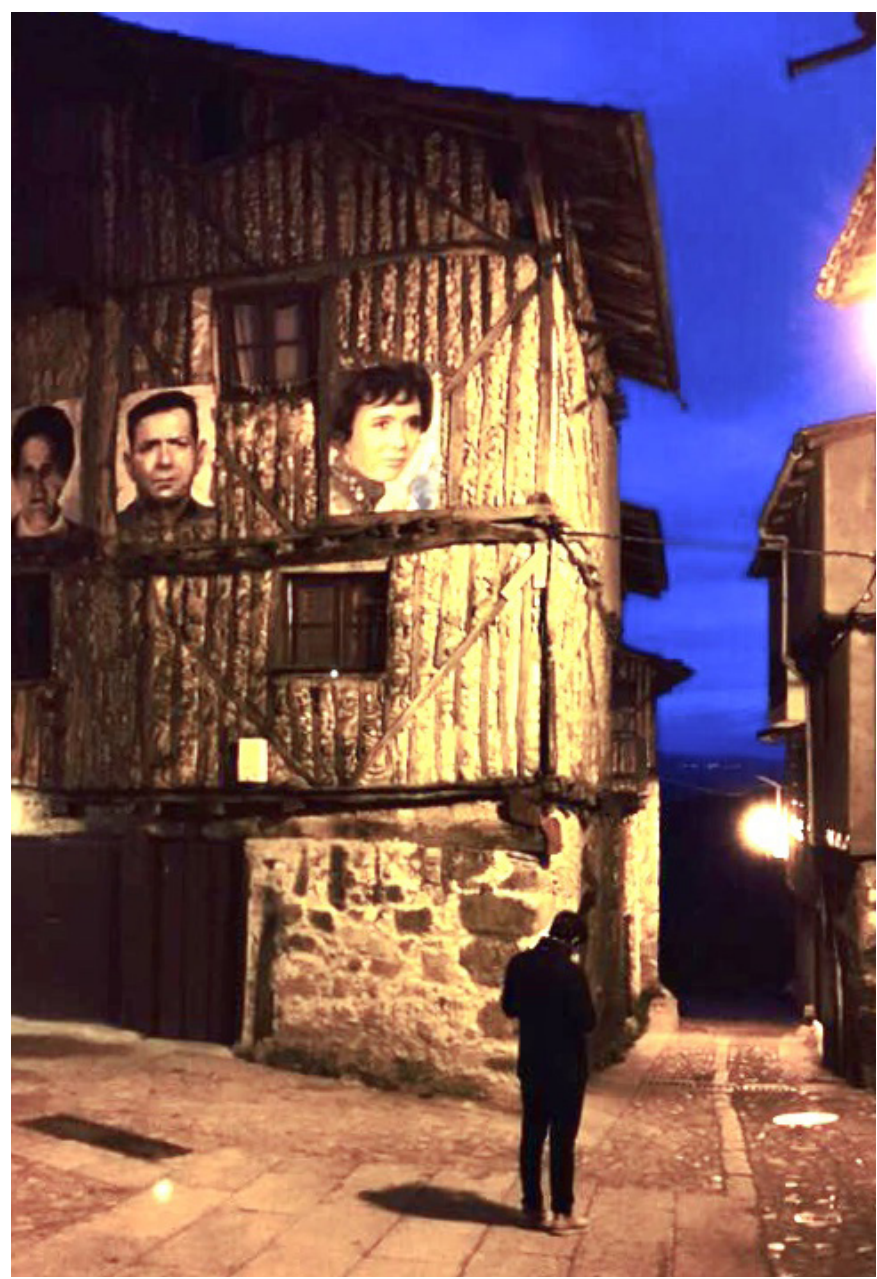

El retrato como acción restauradora de la memoria en un medio montano patrimonializado. Proyecto de Florencio Maíllo en Mogarraz, Sierra de Francia (Salamanca) | foto Sandra Rodríguez Sánchez

pretado y correctamente gestionado si el colectivo más afín experimenta una merma o se distancia de aquel. Una dinámica demográfica negativa afecta a la preservación, primeramente en lo inmaterial, aunque tampoco lo material sobrevive si desaparecen la intención y los medios para ello. En este contexto de reto demográfico, el repoblamiento constituye una solución bajo dos condiciones: por un lado, que se mantengan las formas de vida y trabajo tradicionales, al menos parcialmente; por otro, que exista garantía de mantenimiento de la memoria colectiva y de la esencia material en aquellos casos en que, habiendo penetrado nuevas pautas socioeconómicas y culturales, se produzca una resignificación del patrimonio (ÁLVAREZ MARTÍNEZ, 2013). En efecto, las oportunidades de revitalización territorial ligadas a nuevos usos y funciones, deben mantener -y no destruir por presión infraestructural o banalización paisajística- las cualidades que singularizan al lugar y a su comunidad (SEVILLA ÁLVAREZ; RODRÍGUEZ PÉREZ, 2019).

\section{Desafíos complejos en el éxito de la ciudad}

La divulgación global de los recursos culturales urbanos, junto a la creciente capacidad para viajar, puede conllevar una demanda y una frecuentación excesivas -más problemáticas si la motivación del visitante es superficial o carece de la sensibilidad necesaria-. Cuestiones como la regulación del flujo de turistas y las modalidades de acceso a los puntos de interés, así como al alojamiento, suscitan un debate continuo cuando se trata de espacios o bienes frágiles, no sólo físicamente sino también en su tejido social (JOVER BÁEZ, 2019). Este es un asunto central por cuanto la percepción del carácter excepcional de un lugar, como se ha señalado, no es plena si la experiencia está desprovista de autenticidad. La turistificación, además, puede originar errores en las localizaciones de nuevas actividades, en los tipos e intensidades de estas, así como disonancias en la introducción de estilos arquitectónicos y de medios técnicos (ESPEJO MARÍN, 2011). Así, a la postre, se reduce el interés del lugar y se resuelve de modo deficiente su renovada orientación socioeconómica.

\section{La investigación y el conocimiento técnico como respuestas}

En las ciudades, cada vez más, la comunidad y el patrimonio mutan como resultado de la presión de agentes interesados en rentabilizar el espacio y sus componentes culturales de modo intensivo, como objeto de consumo y fuente de riqueza, en un contexto de competencia territorial de amplio alcance (FERNÁNDEZ SALINAS; SILVA PÉREZ, 2017). No es sencillo dirimir esta cuestión desde la óptica del mercado pero, desde luego, nuestras instituciones disponen de asesoramiento y herramientas para que el mercado interprete adecuadamente los 
a debate ¿Hay patrimonio sin comunidad? Despoblamiento, turistificación y patrimonio cultural

| coordina Jaime Jover Báez

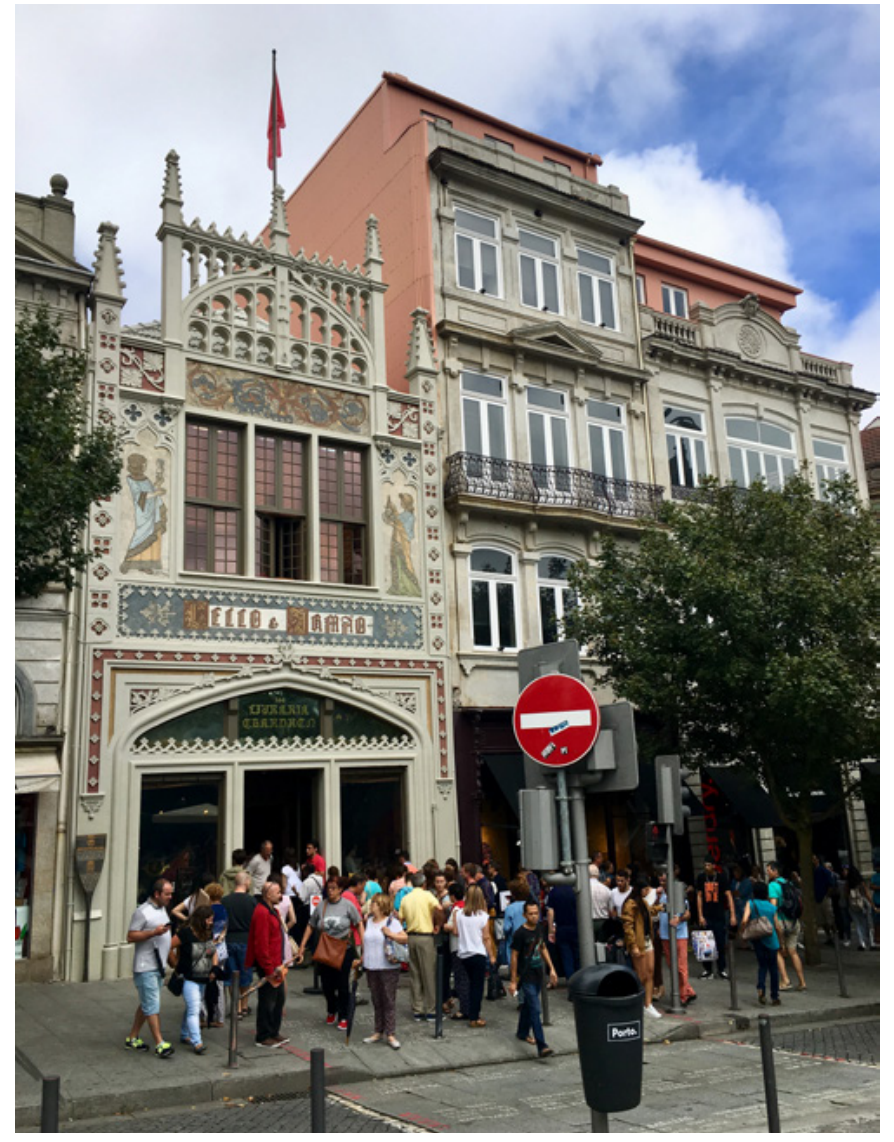

Desnaturalización de un establecimiento comercial singular por el turismo urbano masificado. Livraria Lello, Oporto, 2016 | foto Juan Sevilla Álvarez

bienes de interés común, como ocurre en otras esferas de intervención ya asumidas. Se impone, por tanto, el diseño y la aplicación de instrumentos de planificación y gestión integrales, no sectoriales, que concilien realmente las acciones de conservación con una promoción turística proporcionada -volumen y rentabilidad no van necesariamente unidos-. En definitiva, no puede haber patrimonio si, en procesos de cambio, las sucesivas actuaciones no subrayan los valores originales ni protegen a la comunidad que los ha vehiculizado.

\section{BIBLIOGRAFÍA}

- ÁLVAREZ MARTíNEZ, M. S. (2013) Patrimonios destruidos/ patrimonios creados. La Ruta del Acero: un locus identitario entre la destrucción y la creación. En ÁLVARO ZAMORA, M. I., LOMBA SERRANO, C.; PANO GRACIA, J. L. (coord.) Estudios de Historia del Arte. Libro Homenaje al Prof. Gonzalo M. Borrás Gualis. Zaragoza: Institución Fernando el Católico, Universidad de Zaragoza, 2013, pp. 99-111

- BÉGHAIN, P. (1998) Le patrimoine: culture et lien social. Paris: Presses de Science Po, 1998.

- BERDOULAY, V. (1992) Les valeurs géographiques. En BAILLY, A.; FERRAS, R.; PUMAIN, D. (ed.) Encyclopédie de Géographie. Paris: Economica, 1992, pp. 385-403

- BOUISSET, C.; DEGRÉMONT, I. (2010) Patrimoines Naturels. Sud-Ouest Européen. Revue Géographique des Pyrénées et du Sud-Ouest, n. ${ }^{\circ}$ 30, 2010, pp. 1-3

- BOUISSET, C.; DEGRÉMONT, I.; SEVILLA, J. (2010) Le patrimoine naturel vu du web: discours, valeurs, fonctions. Sud-Ouest Européen. Revue Géographique des Pyrénées et du Sud-Ouest, n. ${ }^{\circ}$ 30, 2010, pp. 85-98

- ESPEJO MARÍN, C. (2011) El paisaje como recurso turístico. En SIMANCAS, M. R.; CORTINA, A. (coord.) Retos y perspectivas de la gestión del paisaje en Canarias. Santa Cruz de Tenerife: Gobierno de Canarias; Santander: UIMP, 2011, pp. 437-462

- FERNÁNDEZ SALINAS, V.; SILVA PÉREZ, R. (2015) Paisajes españoles susceptibles de ser incluidos en la Lista de Patrimonio Mundial de Unesco. Criterios para su identificación y selección. Boletín de la Asociación de Geógrafos Españoles, n. ${ }^{\circ} 68,2015$, pp. 253-278

- FERNÁNDEZ SALINAS, V., SILVA PÉREZ, R. (2017) EI patrimonio en la reinvención de Málaga: Agentes, instrumentos y estrategias. Investigaciones geográficas, n. ${ }^{\circ}$ 67, 2017, pp. 81-100

- GUILLAUME, M. (1990) Invention et stratégies du patrimoine. En JEUDY, H. P. (dir.) Patrimoines en folie. París: Ministère de la Culture et de la Communication, Édition de la Maison des Sciences de l'Homme, 1990, Cahier 5, pp. 12-20

- JOVER BÁEZ, J. (2019) ¿Hay patrimonio sin comunidad? Despoblamiento, turistificación y patrimonio cultural. Revista $P H$ [en línea], n. ${ }^{\circ}$ 98, 2019. <www.iaph.es/revistaph/index.php/ revistaph/article/view/4516> [Consulta: 01/07/2019]

- LOIS GONZÁlEZ, R. C.; PIÑEIRA MANTIÑÁN, M. J.; SANTOMIL MOSQUERA, D. (2010) La imagen del rural en la promoción turística de Galicia. Oceánide, n. ${ }^{\circ} 2,2010$, p. 3

- ORMAETXEA ARENAZA, O.; LUCIO FERNÁNDEZ, J. V. DE (1992) Valoración de la calidad del paisaje vasco por la población. Métodos para su consideración objetiva como 
criterio de conservación. Cuadernos de Sección Historia, n. ${ }^{\circ}$ 20, 1992, pp. 491-504

- RODRíGueZ GUTIÉRREZ, F. (2012) Región y desarrollo. En IEPC (ed.) Cursos a Distancia 2012. Curso Desarrollo Comunitario y Sostenible. Oviedo: Instituto de Estudios para la Paz y la Cooperación, 2012, pp. 1-41

- SEVILla ÁlVAREZ, J.; RODRígueZ PÉREZ, c. (2019) Relevancia y desafíos del paisaje en la formación de una imagen turística de prestigio: la costa de Llanes (Asturias). Cuadernos de Turismo, n. ${ }^{\circ} 43,2019$, pp. 435-469

- ZUBE, E. H.; SELL, J. L.; TAYLOR, J. G. (1982) Landscape Perception: Research, Application and theory. Landscape Planning, vol. 9, n. ${ }^{\circ} 1,1982$, pp. 1-33 